\title{
\# THE TRAININg OF ABORIgINAL PEOPLE AS TEACHERS IN TRADITIONAL COMMUNITIES LINKED WITH A CAREER STRUCTURE FOR ABORIGINAL TEACHERS
}

${ }^{*}$ C.D. Metcalfe

This submission will not seek to argue the need for teacher training for traditional Aborigines. This has been adequately presented in Hubble (1982), in Neville Green's submission to the Inquiry, and the article by John Sherwood, which Mr Green quotes. His opening paragraph is reproduced here:

\begin{abstract}
Here is a disturbing fact to which we must respond. Western-style education has not enabled even one traditionally oriented Aboriginal in Western Australia to qualify as a teacher in more than 100 years. It is unlikely to do so while it operates as at present. A realistic alternative model is needed in order to train members of traditional Aboriginal communities for increasing responsibilities, including teaching, in their schools. This is not, as some say, an impossible dream: it is a challenge.
\end{abstract}

(Sherwood 1982:43)

In addition to the need to answer this challenge, there also exists a pressing need to provide a graduated career structure in teaching for Aboriginal people. For many years Aborigines and educators in a number of states have been pressing for a middle order category of teaching positions particularly related to Aborigines teaching in their own communities. By creating such community-specific positions and using them to link teacher aide positions with Diploma of Teaching courses, a full career structure would be provided.

The outline of this submission will be set out in diagrammatic form and then various facets of the diagram will be discussed.

* Dr C.D.Metcalfe, Dept.of Aboriginal and Intercultural Studies, W.A.C.A.E., Mt Lawley Campus, W.A. 6050

\# This article is a slightly modified version of a submission to the Beazley Inquiry. The Inquiry was established under the chairmanship of Kim Beazley Snr. in March, 1983, by the Burke government to inquire into education in Western Australia. Mr Beazley was formerly the Minister for Education in the Whitlam government. 


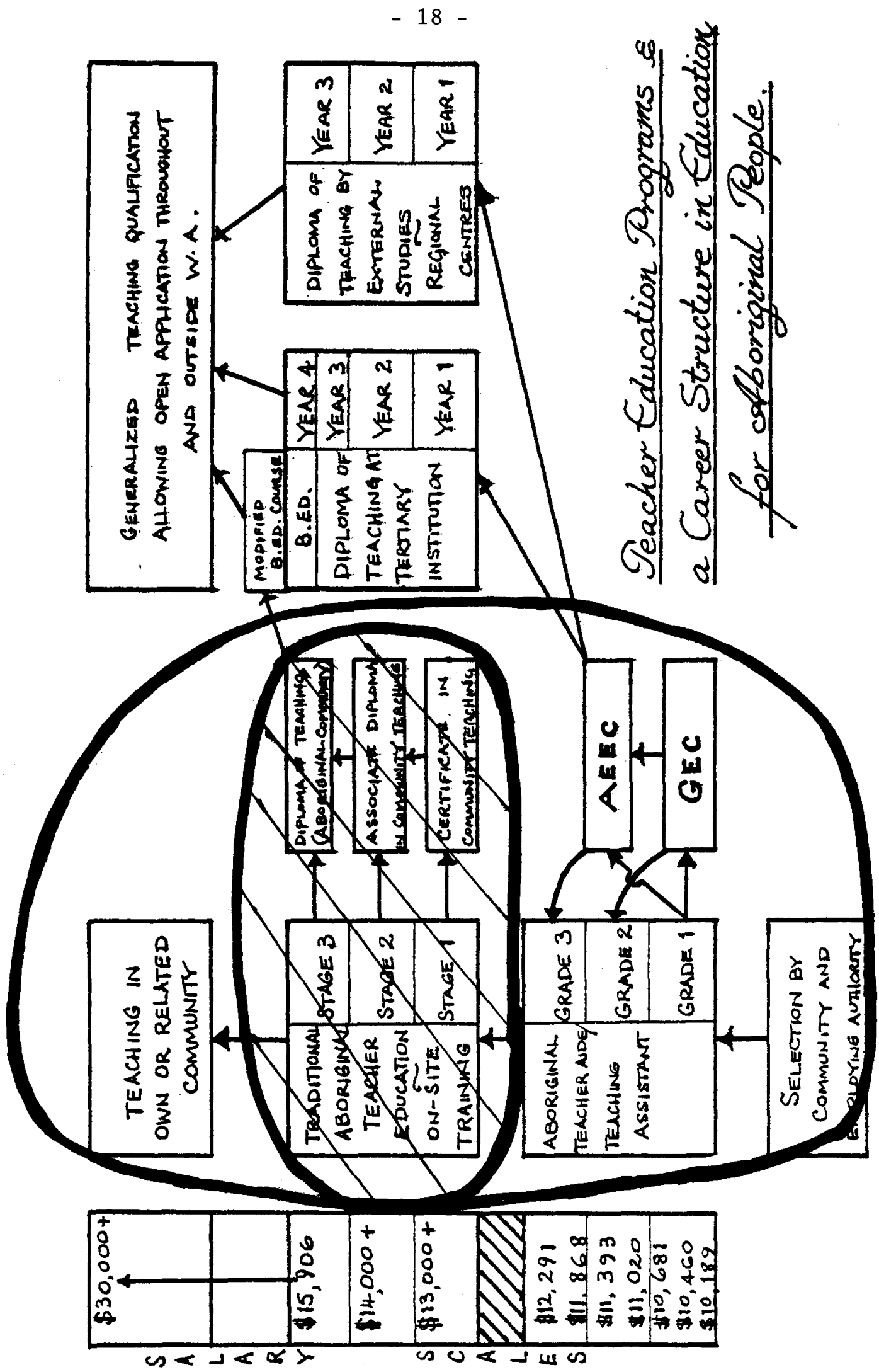




\section{DISCUSSION OF DIAGRAM}

1. The only area of the diagram which does not exist at present has been hatched and much of the discussion will centre on this segment.

2. Commencing from the bottom of the chart we see that the selection of Aborigina1 teacher aides (WA Education Department) and teaching assistants (Catholic Education Commission) is a matter of consultation between the community and the employing authority. In the case of Strelley and other associated Nomads' Foundation schools the community and the employing authority coincide. In each school system the main criterion is that the person is a member in good standing of the local community. Most of the details outlined in this paper refer more specifically to Departmental teacher aides.

3. Aides are graded at three levels with seven increments. Salaries range from $\$ 10,189$ to $\$ 12,291$. Increments are gained generally after each year of satisfactory service. There is growing acceptance, however, of the use of the General Education Certificate (GEC) and the Advanced Education Entry Certificate (AEEC) as means for accelerated promotion. This is indicated in the diagrams by the arrows linking the Grades with the courses. GEC and AEEC are external courses for Aboriginal people at the pre-tertiary leve1. There are some 200 students at present enrolled.

Although salary levels and award provisions of the Aide positions are generally well accepted, there are no promotional possibilities past the final increment. This lack of a career stmucture, particularly for people in traditionally oriented communities, is one of the main concerns of this submission. Although the upper level of $\$ 12,291$ p.a. is seen as a reasonable salary, there is a large gap between this figure and the commencing salary of nearly $\$ 16,000$ for a 3-year-trained teacher ranging up to over $\$ 30,000 \mathrm{p}$.a. in the teaching career structure.

4. Theoretically, there are at least two possibilities for further training and advancement. Aboriginal people can apply to a tertiary institution for acceptance to do a Diploma of Teaching or Bachelor of Education. They may gain 'normal' entry, or relaxed entry through one of the Aboriginal student intakes. However, it is not a viable 
option for most non-urban Aborigines to spend three to four years in Perth away from family and community. Reasons for the non-suitability, and even danger, of such courses have been we11 argued by John Sherwood, Neville Green, Doug Hubble, and others and will not be discussed here.

5. The second option is to enter a course of training at a regional centre. At present two such courses for a Diploma of Teaching by external studies are operating at Broome and Derby. More are planned, but they will always be very restricted in operation. Even then, they do not meet the needs of most people in more traditional areas.

6. Some teacher aides are becoming eligible for long service leave. Many, because of their permanent community residence and their long school service, are a vital factor in the stability and continuity of educational programs. Their home and community liaison role is also of extreme importance. They are, however, in a dead-end situation if it is not feasible or advisable for them to attend a tertiary institution or regional centre.

7. The values of community membership and Aboriginal identity should be recognised and capitalised upon in the planning, development and delivery of educational services to Aboriginal communities. Training and a career structure must be developed for Aborigines who do not or cannot leave their communities for three to four years.

8. A Traditional Aboriginal Teacher Education Program is the title at times given to proposed courses in teacher education based largely on on-site training and external studies. What has been proposed here and by Sherwood, Green, and Hubble, closely parallels the South Australian Anangu Teacher Education Program (ANTEP).

"Anangu" is a central reserve area word meaning "Aboriginal person" and ANTEP is a teacher training program for the relatively traditionally oriented communities in northern South Australia. Although much of the development of the WA proposals has been independent of the SA submission, much can be shared and a co-operative basis for the development and implementation of the programs could well be considered, a move already fore-shadowed by Senator Susan Ryan. South Australia is well ahead of Western Australia as ANTEP is at present undergoing the accrediting process with the state's 
Tertiary Education Authority. The Northern Territory has, of course, for many years offered a full career structure for Aboriginal teachers from teaching assistants through to full recognition in the Northern Territory Teaching Service.

9. Turning in more details to the proposed Traditional Aboriginal Teacher Education (TATE) program for Western Australia, the following points are made:

9.1 TATE is basically an on-site training program. It would be implemented by local lecturers/coordinators and tutors and would be strongly related to the wider community educational program. It could also involve short periods of time at a tertiary campus or regional centre and visits from lecturers from these centres; as with the Broome course. It could take in a number of related communities. For instance, a course could be conducted at Warburton Ranges to service the related "out-station" communities or at Strelley station in conjunction with other schools in the "Nomads" group. But Aboriginal adults, many with young families, would not have to move away from their traditional communities for extended periods of time.

9.2. TATE could be supported by external studies. The local lecturer/coordinator or tutor would have the back-up support of externalised courses prepared and serviced by lecturers from the central teacher education institution. The extent of this support and areas in which it is appropriate would have to be discussed at greater depth, and over-centralised control would have to be avoided.

9.3. TATE would be a flexible and multi-exit training and certification program. It has been set out in three stages rather than years. Each stage would normally be completed after a one year full-time course. However, students could exit from the program at the successful completion of each stage and be awarded a terminal qualification with attendant status, salary and wider educational responsibilities. Each completed stage would allow progression to the next either immediately or after some school service.

The awards could be given descriptive titles such as:

Stage 1 - Certificate in Community Teaching

Stage 2 - Associate Diploma in Community Teaching.

Stage 3 - Diploma of Teaching (Aboriginal Community). 
9.4: TATE qualifications would be comminity specific. Though the Diploma of Teaching (Aboriginal Community) would have the same salary, legal standing and status as any other accredited Diploma of Teaching award once it has been accepted, it would allow the graduate to teach only in his or her own community or other community closely related to it. This has been a stumbling block in the past as it has been suggested that a qualification which restricts the area of teaching is somehow inferior. However, this argument is now widely refuted as many teaching qualifications are restricted to particular areas. For instance, a secondary teaching mathematics graduate would be incensed if told that his qualification was second rate because it did not qualify him to teach a pre-school class or even a high school home economics group. Conversely, there is inestimable value in the teachers in traditional communities being resident members of that community.

9.5 TATE would become the link providing a full career structure for traditional Aboriginal people. Referring to the diagram it will be seen that people could embark upon a sequential career from teacher aides/teaching assistants through to qualified teachers within the various employing systems. Further training and advancement would allow for the gradual Aboriginalisation of the community educational services and advancement in responsibility and salary. Adult teacher aides commence at $\$ 10,189 \mathrm{p}$.a. and can progress to $\$ 12,291 \mathrm{p}$.a. on present (August 1983) figures. At each level of exit from the training program, salary increments would have to be provided. A Certificate might allow a salary of $\$ 13,000+$, an Associate Diploma $\$ 14,000+$ and a Diploma of Teaching at the present commencing level of $\$ 15,906$. This could all be accomplished within the context of the person's own community (area indicated by outer boundary.)

If a person holding a Diploma of Teaching (Aboriginal Community) wished, for community or individual purposes, to generalise his or her qualification, it might be possible to provide a bridging course at a centralised institution to allow for an open application for a teaching position throughout or outside Western Australia. This would also, as a long-term goal, make it possible for Aborigines from more traditional areas to move into positions of authority and control within the various educational systems. 
REFERENCES

Green, N.: Submission to the Beazley Inquiry into education in W.A. Unpublished paper, Mount Lawley, 1983.

Hubble, D.: Alternatives for Aboriginal teacher education. In J.Sherwood, (Ed.): Aboriginal Education: Issues and Innovations. Creative Research, Perth, 1982.

Sherwood, J.: Traditional Aborigines as full teachers: towards the development of a new model. Wikame 10, May 1982. WACAE Mount Lawley, W.A.

The Anangu Teacher Education Program (ANTEP). A submission to the Tertiary Education Authority of South Australia, Underdale Campus, June 1982.

\section{THE ABORIGINAL CHILD AT SCHOOL}

A National Journal for Teachers of Aboriginals

5 issues per year

Subscription period - January/December

Individuals, institutions, 1ibraries etc. $\ldots \$ 10.00$

Teacher Aides

$\ldots \$ .00$

Overseas.......\$12.50

(Schools with a significant Aboriginal enrolment are entitled to one free copy of each issue. Schools with large Aboriginal enrolments are entitled to two free copies of each issue).

Cheques etc. payable to - The Aboriginal Child at School Aboriginal Education (Munro St) University of Queensland St Lucia 4067

Enquiries: (07) 3772388 